\title{
ARS MEMORATIVA, ABEJAS Y MIEL EN LA CELESTINA
}

\section{ARS MEMORATIVA, BEES, AND HONEY IN LA CELESTINA}

\author{
Adam Alberto Vázouez Cruz \\ University of Saskatchewan \\ adam.vazquez.cruz@gmail.com
}

Resumen: En este artículo se analiza el texto celestinesco desde la perspectiva del arte de la memoria. Gracias a la caracterización de la alcahueta como abeja y de los amantes como flores, se abre una posibilidad interpretativa que echa mano de una analogía ampliamente usada para describir los procesos intelectivos. Ésta descansa en una comparación entre los procesos para elaborar miel y para generar discurso. Celestina, por medio de la palabra, manipulará a los personajes, pero su falta de prudencia la llevará a la muerte. Este artículo pretende ampliar nuestro entendimiento de La Celestina al explorar una de las tradiciones que evoca.

Palabras clave: miel; abeja; memoria; tejido; discurso.

Aвstract: This article analyzes La Celestina from the perspective of the art of memory. Due to the characterization of Celestina as a bee and the comparison of the lovers as flowers, it is possible to read the text in terms of an analogy that was widely used to describe intellective processes. This analogy compares the process to produce honey to the process that produces discourse. By masterly using language, Celestina manipulates the rest of the characters, but her lack of prudence will lead to her death. This article intends to broaden our understanding of the work by exploring one of the traditions it evokes.

Keywords: honey; bee; memory; weave; discourse.

Recepción: 26 de abril de 2017; aceptación: 12 de septiembre de 2017.

D.R. (C) 2018. Nueva Revista de Filología Hispánica Licencia Creative Commons Attribution-NonCommercial (CC BY-NC) 4.0 International 
In memoriam Mateo Vázquez Morales

Miel, intento traerles mi miel -la miel de mi reflexión sobre lo que, mi Dios, hago desde hace cierta cantidad de años.

JACQUES LACAN

La miel se ha insertado en la cultura como elemento provechoso para el ser humano, ya sea que la encontremos como remedio para enfermedades en obras que describen la naturaleza, o en diversos tratados como metáfora del conocimiento. Dulce y refinada, la miel está inevitablemente ligada a las abejas, que en el imaginario, junto con las hormigas, se han representado como insectos trabajadores. La miel, por tanto, es el resultado del trabajo arduo. Este símil no es nuevo, aunque sí muy sugerente, por lo que podemos encontrarlo desde Quintiliano hasta Lacan.

En el presente trabajo quiero explorar este tema, que reviste particular interés, y señalar cuál es la importancia del símil en La Celestina, ya que la alcahueta es descrita como abeja, mientras que Calisto y Melibea lo son, a su vez, como flores. Me propongo mostrar esta relación, además de discutir la concerniente a discurso y tejido, para hacer hincapié en que las descripciones, además de ofrecer claves de lectura, se apoyan en referentes culturales que las llenan de sentido, como las ars memoriae y el discurso científico clásico, entre otros. Finalmente, con la información obtenida, podremos ver desde una nueva perspectiva el significado de los nombres de dos personajes: Melibea, con su debida referencia a la miel, y Celestina, a los cielos. Todo lo anterior tiene como propósito desentrañar uno de los muchos hilos que tejen el texto celestinesco.

En el auto sexto, cuando Celestina vuelve de casa de Melibea y va a la de Calisto para rendirle cuentas, el joven mancebo, desesperado, pide a Celestina que le diga cómo reaccionó Melibea: "certifícame brevemente si hovo buen fin tu demanda gloriosa”. Es entonces cuando Celestina se describe a sí misma como abeja:

La mayor gloria que al secreto oficio de la abeja se da, a la qual los discretos deven imitar, es que todas las cosas por ella tocadas convierte en mejor de lo que son. Desta manera me he havido con las çahareñas razones y esquivas de Melibea. Todo su rigor traygo convertido en miel, su yra en mansedumbre, su aceleramiento en sosiego (Rojas 2001, p. 339). 
Discurso y ARTE DE LA MEMORIA

Conviene situar en qué otros contextos la miel ha sido empleada como sinónimo del discurso. Peter Russell remite a Petrarca como fuente de la cita; sin embargo, se trata de un tópico que puede rastrearse hasta la época clásica. Todo parece indicar que la primera referencia documentada está en Longino, pero él mismo sugiere que usa una metáfora bien establecida (Carruthers 2008, p. 44). Carruthers (id.) señala que Quintiliano equipara al orador, quien moldea su elocuencia a partir de diferentes artes y disciplinas, con las abejas que convierten varios tipos de flores y jugos en el sabor de la miel, obra que ningún talento humano puede imitar. Según W. Telfer (1927, p. 169), este mismo uso lo podemos encontrar en Clemente de Alejandría cuando llama a su maestro (parece referirse a Panteno) "abeja sícula". Panteno, en su labor de exégeta del Antiguo y del Nuevo Testamento, entresaca la esencia pura de la gnosis del mismo modo en que las abejas extraen miel de las flores. De esta manera, vemos que aquel que produce discurso, o quien lo interpreta, puede compararse a la abeja, cuya miel es el conocimiento.

Este símil tiene eco en la tradición cristiana. En Pr 24:13-14 se aconseja: "come miel, hijo mío, que es buena, y el panal es muy dulce al paladar. Así es, sábelo, la sabiduría para tu alma; si la encuentras, tendrás buen porvenir, y tu esperanza no quedará incumplida". La miel es equiparada a la sabiduría, por lo que no extraña que en la tradición clásica tardía y en la medieval esta comparación tenga buena acogida. Apunta W. Telfer que la miel para Clemente simboliza el dulce y provechoso conocimiento del logos, que debe ser entresacado del variado jardín del universo (1927, p. 177).

Ricardo de Bury asimila la labor de quienes acumulan libros al de las abejas que almacenan miel en las celdas de la colmena (Carruthers 2008, p. 45). Asimismo, Ricardo de Fournival, autor conocido por el Bestiaire d'amour, proveyó en su Biblionomia una guía a través de su biblioteca personal presentada como un paseo alegórico en un jardín (Clemens 2007, p. 62), lo que recuerda, sin duda, el variado jardín del universo de Clemente de Alejandría. Podemos esbozar una analogía en que los libros son las flores de las que liban los estudiosos, quienes por medio de su proceso de intelección elaboran un discurso tan provechoso como la miel. Si extendemos la analogía al texto celestinesco, la alcahueta está convertida en abeja y Melibea es la flor 
cuyas palabras, mediante el oficio de Celestina, se convierten en dulce respuesta para Calisto.

Hay que señalar que esta analogía no es gratuita; en realidad tiene un hondo arraigo en las descripciones de los procesos intelectivos contemporáneos a la obra. La memoria ocupa en la Edad Media el lugar privilegiado de la originalidad en nuestros días, por lo que cualquier modelo epistemológico la tendrá por fundamental. Las ars memoriae son a la vez síntoma y producto de lo anterior. Aunque no es el propósito de este trabajo hacer una revisión exhaustiva de ellas, vale la pena mencionar que, según Carruthers, todos los esquemas mnemónicos organizacionales son heurísticos en naturaleza; son esquemas de recolección con la inventio como finalidad (2008, p. 23), pero sin estructura fija, ya que su naturaleza es puramente funcional, es decir, sirven para recordar, no para interpretar. Los esquemas mnemónicos, necesarios, pues los elementos que se desean recordar deben estar ordenados ${ }^{1}$, fincan su validez en la efectividad para llevar a cabo la recolección.

Todos los autores que escriben sobre el tema exhortan a sus alumnos a crear esquemas propios, cuyas relaciones descansen en sus hábitos de pensamiento en vez de depender de los modelos de otros (Carruthers 2008, p. 24). Este proceso de recolección, en el que Carruthers hace tanto hincapié, es fundamental para entender cómo se concibe la memoria. La recolección es un proceso consciente que se da por medio de la asociación: uno encuentra o persigue el recuerdo-impresión almacenado gracias a que está unido a otros elementos, ya sea a través de un proceso lógico o bien por causa de la costumbre. Si la inventio es el propósito final, debemos entender que, por poner un ejemplo, el orador podrá echar mano del conocimiento almacenado en su memoria para relacionarlo de maneras novedosas y poder persuadir a la audiencia con su discurso. Éste es el tipo de relaciones que las artes memorativas enseñan (Carruthers 2008, p. 23).

Carruthers (p. 30) señala que la mayoría de los autores premodernos pensaba en el conocimiento como una colección de verdades a la espera de hacerse expresar mediante el len-

1 Frances Yates (1999) cita la Summa de exemplis ac similitudinibus rerum de Giovanni di San Gimignano, escrita en el siglo xiv, en que se establece: "There are four things which help a man to remember well", de las cuales la primera es "that he should dispose those things which he wishes to remember in a certain order" (p. 85). 
guaje humano en contextos pertinentes. Esto quiere decir que hay una multiplicidad notable de formas específicas para abordar cualquier tema. Lo anterior es comprobable, por ejemplo, si damos un vistazo a un compendio como Disciplina clericalis, en que bajo un rótulo como el del amigo completo, podemos encontrar cuentos ejemplares a la vez que proverbios sobre el mismo contenido. Éstos son ejemplos de las formas particulares que pueden emplearse para explicar un tema, distinto de lo que ocurre con un diccionario moderno, en que se encuentran definiciones que pretenden tener un cierto grado de universalidad. De esta manera, el orador puede recurrir a un ejemplo o a otro según requiera.

Carruthers (2008, p. 30) señala que la memoria de un orador es como un almacén de temas inventariados que, idealmente, contendría todas las formas de poner en palabras verdades éticas como la justicia, la valentía o la templanza, de las cuales el orador echará mano para expresarse decorosamente según la ocasión. Este almacén debe ser imaginado como una serie de compartimientos que están vacíos cuando nacemos y se van llenando con varias "monedas" o "flores" o "néctar", cuya acumulación es una forma significativa, aunque parcial, de expresar la justicia o cualquier otro tema. Cada expresión de la "justicia" se añade al almacén.

Para nuestros propósitos, es recomendable tener en mente no sólo la idea de la memoria como un almacén, sino también la mención de las flores y el néctar. He de señalar además que el alcance de la analogía no se queda en la alusión a elementos sueltos como flores, miel y abeja, sino que a partir de ellos se compone un entramado para dar cuenta de la actividad de recordar. El sentido metafórico del almacén es sólo uno de los muchos que se pueden elegir para ilustrar los procesos de intelección y memoria. También se emplean otras analogías: el tesauro, en el que se encuentran tesoros -entiéndase conocimiento- de una manera ordenada, o bien un cofre en el que se guardan bienes en sus distintos compartimientos.

Es de interés particular en este trabajo detenerse a considerar cómo la metáfora del almacén se liga con la del panal. Carruthers (2008, p. 41) comenta que cella, la palabra usada por Geoffrey de Vinsauf para la memoria (a la que llama cellula deliciarum), también significa 'almacén', acepción que aún conserva el término cellar del inglés, 'bodega, sótano', descendiente de cella y de la forma derivada cellarium. También señala que 
la palabra latina cella tiene otros usos más especializados que la unen a otras metáforas comunes tanto para la memoria como para el estudio, al igual que ocurre con palabras como arca y thesaurus.

Cellae, además, son los lugares en que animales domésticos y aves hacen su nido. En latín clásico, el palomar recibía el nombre de cella columbarum. Los compartimientos hechos por las abejas para su miel también son llamados cellae (aún son llamadas cells en inglés y celdas en español). Concluye Carruthers (p. 42) que existe un tejido de metáforas que asimila el almacenamiento de recuerdos en la memoria entrenada con el cuidado de aves (especialmente de palomas) y con la producción de la miel por parte de las abejas.

A su vez, la memoria entrenada se asimila a una biblioteca, en lugar de un panal, en que las celdas van a ser los libros o bien las flores de las que liben los estudiosos. Los elementos se relacionan para dar sentido al símil: la cadena se completa por la conexión metafórica de los libros en una biblioteca, los recuerdos ordenados en celdas de la memoria y las aves y abejas en las celdas de sus palomares y colmenas (pp. 41-42). De esta manera, notamos la contigüidad del ejemplo del orador en Quintiliano, la del exégeta en Clemente de Alejandría, la de quien acumula libros en Ricardo de Bury y también la forma en que la sabiduría se caracteriza como miel en Proverbios. En palabras de Séneca: "debemos, según dicen, imitar a las abejas que revolotean de aquí para allá y liban las flores idóneas para elaborar la miel; luego el botín conseguido lo ordenan y distribuyen por los paneles" (Epístola 84).

\section{LAS ABEJAS Y LA MIEL EN LOS TRATADOS CIENTÍFICOS}

Dentro de las obras que describen la naturaleza encontramos varias razones que dejan ver por qué las abejas y su labor sirvieron como analogías dignas del pensamiento humano. Ya señala Plinio en su Historia natural que "entre todos los insectos el primer puesto es para las abejas y también, con todo derecho, nuestra mayor admiración pues son los únicos de esta clase de animales creados para bien del hombre" (XI, 11). Plinio destaca que la miel es "jugo dulcísimo y finísimo y muy saludable" (XI, 11). Las abejas huyen de la suciedad y de los malos olores (Aristóteles 1992, 535a, 2-4; 596b, 15; Plinio 2002, XI, 44 y XI, 
61; Telfer 1927, p. 169), y también han sido asociadas con la castidad (Telfer 1927, p. 169). Aristóteles, en Investigación sobre los animales, señala que "en cuanto a la generación de las abejas, no todo el mundo está de acuerdo, [ya que] unos pretenden que las abejas no paren ni se acoplan" (533a, 21), y Plinio comenta que "nunca se ha visto el apareamiento de las abejas. Muchos han creído que formaban la cría con la boca a partir de flores dispuestas en la forma adecuada" (XI, 46), idea que Aristóteles comparte cuando apunta que "depositan en él [el panal] la cría que, como dicen algunos (los que afirman que se la procuran de algún otro sitio), la sacan de la boca" (553b, 25). Las abejas y la boca tienen aún otro vínculo: "se dice que las musas las enviaron a alimentar con miel a algunos infantes que se distinguirían por su elocuencia, su poesía u otras cualidades maravillosas" (Telfer 1927, p. 168). Al respecto, Plinio asevera que "se posaron en la boca de Platón cuando sólo era un niño, presagiando la suavidad de su dulce elocuencia" (XI, 55). Es imposible no pensar en Celestina, cuya principal y más eficaz herramienta es la lengua. En conclusión, las asociaciones de las abejas, insectos que surcan el cielo, suelen apuntar hacia lo favorable.

Con respecto a la producción de la miel, que es lo que más nos compete, ésta no proviene directamente de las flores. Plinio señala que

la miel procede del aire, sobre todo al aparecer las estrellas... al despuntar la aurora, las hojas de los árboles se encuentran húmedas de miel; y si alguien ha estado al raso desde temprano, nota las ropas empapadas de líquido y el cabello pegado, ya sea aquello el sudor del cielo o una especie de saliva de las estrellas o una destilación del aire al purificarse (XI, 30).

Aristóteles, a su vez, dice que "en cuanto a la miel, no la elaboran, sino que la recogen cuando ha caído" (554a), por lo que Virgilio iniciará su cuarta Geórgica de la siguiente manera: "prosiguiendo cantaré el don divino de la miel, que baja de los cielos" (p. 358).

La miel requiere de cierto proceso para alcanzar la forma en que la conocemos. Plinio brevemente apunta que "macerada en las colmenas y sometida a tantas alteraciones, sin embargo proporciona un gran placer por su naturaleza celestial" (XI, 31). En cambio, Aristóteles se extiende y dice que 
cuaja mediante un proceso de cocción. En efecto, al principio es como el agua y durante algunos días permanece líquida (por ello si se la extrae durante estos días no tiene densidad), pero en una veintena de días cuaja. Se reconoce enseguida por el gusto, pues se distingue por su dulzura y densidad. La abeja saca miel de todas las plantas que producen flor en un cáliz, y de todas las que tienen un sabor dulce, sin dañar ningún fruto. La abeja coge los jugos de estas flores con el órgano parecido a la lengua (Aristóteles 1992, 554a, 8-15).

La miel no es materia prima, requiere que las abejas la coloquen en las celdas del panal para trabajar en ella e iniciar su proceso. A partir de aquí, se puede tender el puente con el texto celestinesco.

\section{Celestina, LA Miel Y LAS Flores}

Celestina iguala su trabajo a la labor de las abejas en lo que al proceso de preparación de la miel se refiere. Así como Aristóteles señala, Celestina va a las flores para recoger esta sustancia inicial -el rigor de la dama-, que por medio de un proceso de cocción se convierte finalmente en la densa y dulce miel que conocemos. Celestina revela cómo gracias a que conoce el oficio, puede descifrar los verdaderos pensamientos de Melibea; señala que este tipo de dueñas

a quien más quieren, peor hablan. Y si assí no fuesse, ninguna diferencia habría entre las públicas que aman, a las escondidas doncellas, si todas dixessen "sí" a la entrada de su primer requerimiento, en viendo que de alguno eran amadas. Las quales, aunque están abrasadas y encendidas de vivos fuegos de amor, por su honestidad muestran un frío exterior, un sosegado vulto, un apazible desvío, un constante ánimo y casto propósito, unas palabras agras, que la propia lengua se maravilla del gran sofrimiento suyo, que la fazen forçosamente confessar el contrario de lo que sienten (p. 340).

Aquí se describe un ejercicio de interpretación: la alcahueta no va a reproducir las palabras de Melibea, sino que de ellas va a entresacar lo más provechoso para su propósito, como lo hará un estudioso que recurre a los libros para argumentar una tesis o para extraer la esencia del texto. Ambos lo convertirán en conocimiento útil, y así como el orador, por cuanto este 
conocimiento es comunicado, va a persuadir a su audiencia, en este caso a Calisto, de persistir en el negocio.

No es gratuito que Celestina diga: "Assí que, para que tú descanses y tengas reposo, mientra te contaré por estenso el proceso de mi habla y la causa que tuve para entrar, sabe que el fin de su razón y habla fue muy bueno" (p. 340). La alcahueta aquí realza el "proceso de su habla", ya que, tanto con Melibea como con Calisto, su conocimiento y su elocuencia, según se mencionó líneas arriba, son su mejor herramienta. Así, la oración final, "el fin de su razón y habla [de Melibea] fue muy bueno", se convierte en la muestra más clara de cómo convirtió el rigor en miel.

Este símil también comprende a los dos jóvenes amantes, pues ambos son flores que liba la abeja Celestina; ocurre de manera matizada con Melibea, pero no olvidemos que Pleberio, en su planto final, increpa a la Fortuna y dice: “’Por qué no quemaste mi morada? ¿Por qué no asolaste mis grandes heredamientos? Dexárasme aquella florida planta en quien tú poder no tenías" (p. 597). Melibea es la "florida planta", sí, en su sentido de 'hermosa', como anota Russell, pero también adquiere otro significado a la luz de lo que se ha expuesto previamente. Algo similar ocurre líneas más adelante cuando, quejándose del Mundo, Pleberio dice: "fasta agora [he] callado tus falsas propiedades por no encender con odio tu yra, por que no me secasses sin tiempo esta flor que este día echaste de tu poder" (p. 598). "Secasses" es un cultismo que significa 'segar': el padre, en este caso, lleva un poco más allá el símil al utilizar un verbo más propicio para la flor que para la hija.

Calisto es nombrado como flor por la alcahueta en su encuentro con la dama. Melibea, enferma, se queja con Celestina de sus males, que la alcahueta diagnostica como padecimiento de "amor dulce", el cual "es un fuego escondido, una agradable llaga, un sabroso veneno, una dulce amargura, una delectable dolencia, un alegre tormento, una dulce y fiera herida, una blanda muerte". La dama reflexiona y dice: "iAy, mezquina de mí! Que si de verdad es tu relación, dudosa será mi salud" (p. 435). Afortunadamente, dirá Celestina, "quando el alto Dios da la llaga, tras ella embía el remedio. Mayormente que sé yo al mundo nascida una flor que de todo esto te delibre", y se da el siguiente intercambio entre ambas mujeres:

MeL.- ¿Cómo se llama?

CEL.- No te lo oso decir. 
MEL.- Di, no temas.

CEL.- ¡Calisto! (p. 436).

Calisto está aquí transformado no sólo en flor, sino en medicamento. Cuando éste muere, Melibea declara a su padre: “Pereció mi remedio!” (p. 581). Ambos amantes fungen como flores gracias a las visitas de Celestina, quien, convertida en abeja, los escucha, reconfigura sus palabras y, cuando va con el otro amante, construye elocuentemente una versión dulce del amado. Los personajes en boca de la alcahueta son perfectas creaciones discursivas que inflamarán la pasión de uno por el otro: Celestina trae miel en la boca.

\section{LA AMBIVALENGIA DE LA MIEL.}

Otro Melibeo en Los cuentos de Canterbury

Hay un par de temas en los que quisiera detenerme; primero, el tópico de la miel como remedio. Es cierto que aquí se ofrece la flor, pero, como ya había apuntado, el alivio viene en primer lugar gracias a la mediación de la alcahueta, de manera que es válido considerar la tradición que avala a la miel como remedio. Aristóteles brevemente menciona que la miel blanca "es buena para los ojos y las heridas" (627a, 4), al igual que Plinio (XI, 38), quien va más allá al señalar que, en verano, "el rocío está tibio por los rayos del sol, lo que se forma no es miel sino auténticos medicamentos, dones celestiales para los ojos, las heridas y los órganos interiores" (XI, 37) ${ }^{2}$. Con esto, cerramos las características positivas de las abejas y la miel, características que de alguna manera dan luz sobre los personajes y que mantendrán una cierta tensión con el desarrollo de la diégesis y con otros significados de los elementos, distintos de los que hasta aquí se han predicado.

${ }^{2}$ El libro XXXII de la Historia natural incluye muchos remedios en los que interviene la miel mezclada con algunos otros ingredientes: "la ceniza de conchas de múrices o de púrpuras con miel es eficaz para los pechos mismos" (129), "el castóreo bebido con vino y miel es bueno para la menstruación" (131), "para las encías de los niños y la dentición es muy buena la ceniza de dientes de delfín con miel" (137), etc. Nos recuerda también al Conde Lucanor, en que se dice "esto fiz segund la manera que fazen los físicos, que quando quieren fazer alguna melizina que aproveche al fígado, por razón que naturalmente el fígado se paga de las cosas dulces, mezclan con aquella melezina que quieren melezinar el fígado, açúcar o miel o alguna cosa dulce" (JuAn Manuel 2003, p. 50). 
El segundo tema por considerar es el de las connotaciones negativas que la miel también tiene. Clemente de Alejandría, por ejemplo, señala que si bien la miel es dulce y buena para los sanos, en los enfermos produce fiebre (Telfer 1927, p. 174). También hay que tener en cuenta que la miel es vomitada por las abejas, fenómeno que Aristóteles menciona por lo menos en un par de ocasiones: "la abeja lleva la cera y el alimento de las abejas alrededor de sus patas, y la miel la vomita en los alveolos" (554a, 18), y "cuando falta el agua corriente, beben en otro sitio, pero vomitan la miel y vuelven enseguida a la tarea" (626b, 27). Plinio dice que "pese a ser bebida de las hojas y de las hierbas y reunida en los pequeños buches de las abejas -pues la vomitan por la boca- [ore enim eum vomunt] y aun corrompida por el néctar de las flores... proporciona un gran placer" (XI, 12).

Para alcanzar una mejor comprensión de la relación de la miel con los personajes y de cómo su ambivalencia puede afectarlos, no está de más acudir a otro ejemplo literario. Entre los Cuentos de Canterbury de Geoffrey Chaucer encontramos el relato de Melibeo, quien, por un lado, comparte el nombre con uno de los personajes principales de nuestro texto hispánico y, por otro, ilustra que el conocimiento tiene que acompañarse de la prudencia para alcanzar su estado virtuoso. Este cuento es de capital importancia dentro de la colección de narraciones cortas ya que, junto con el Cuento del párroco, es el único escrito en prosa. Éste no es un detalle menor; recordemos las palabras del narrador de este último relato:

No conseguiréis fábulas de mí -replicó el Párroco-. Pues, en su Epistola a Timoteo, Pablo riñe a los que se apartan de la verdad y cuentan fábulas y tonterías así. ¿Por qué mi mano debe sembrar la broza cuando lo que deseo es poder sembrar el grano de trigo? Por tanto, digo que, si queréis oír algún asunto moral y edificante y estáis dispuestos a prestarme atención, entonces tendré sumo gusto, con la bendición de Cristo, en daros el placer legítimo que pueda. Pero soy un sureño, no lo olvidéis; no soy partidario de esta aliteración rum-ram-raf, ni creo que la rima sea mucho mejor, Dios lo sabe. Por lo tanto, si no os importa, no usaré estos artificios, sino que os contaré un cuento satisfactorio en prosa para terminar con el juego y ponerle fin (Chaucer 2006, p. 554).

El párroco desprecia el resto de los cuentos hasta aquí narrados y compara estas "fábulas" con la "broza" que no desea sembrar. Su narración, por tanto, será como el trigo, el cereal que 
se convierte en pan y que está en estrecha relación con la comunión; de ahí que esta comparación no sea trivial. El cuento del párroco se distingue por su contenido "moral y edificante". También así será en lo referente a la forma: a diferencia de los otros relatos, no usará el verso, ya sea aliterativo (eso explica el "rum-ram-raf") o rimado; en lugar de esos "artificios" va a narrar un cuento en prosa. Si el cambio de verso a prosa en la narración final de los Cuentos de Canterbury responde a un cambio de tono y de contenido, es válido pensar que lo mismo ocurre con el cuento de Melibeo.

Este relato de Chaucer reúne gran variedad de autoridades, como Séneca, Cicerón, Ovidio, Pedro Alfonso, las Escrituras, etc. A su vez, es conveniente recordar que éste es el relato que cuenta el peregrino Chaucer: en varios testimonios, como en los impresos de Caxton, se llama a este relato Cuento de Chaucer (en Cx1 en el folio 265v se lee una rúbrica que anuncia el cuento como "Sequitur Chawcers tale"; en Cx 2 vemos en el folio 229r que el título reza: "The tale of Chaucer"). ${ }^{3}$. Todo lo anterior deja ver por qué es interesante tomarlo como punto de referencia para nuestro análisis de La Celestina.

Este cuento trata del ataque a Sofía, hija de Melibeo y de Prudencia. No se puede ignorar que los nombres de los personajes están cargados de significado. Sofía es atacada en pies, manos, oídos, boca y nariz, a saber, sinécdoques de cuatro de los cinco sentidos: las ventanas del cuerpo por las que entra información para transformarse en conocimiento y, a su vez, partes del cuerpo cuyo lugar en la tradición cristiana no debe pasarse por alto ${ }^{4}$. Melibeo decide que quiere vengarse de los agresores y convoca a varios de quienes dicen ser amigos suyos para

${ }^{3}$ Ambos folios se pueden consultar en http://www.bl.uk/treasures/ caxton $/$ record.asp?LHPage $=265 \mathrm{v} \&$ LHvol $=\&$ LHCopy $=1 \&$ RHPage $=229 \mathrm{r} \& R$ Hvol=\&RHCopy $=2 \&$ disp $=\mathrm{d} \&$ Linked $=0 \#$ DispTop .

${ }^{4}$ En el Itinerarivm mentis in Deum, san Buenaventura escribe: "Recuperados los sentidos espirituales mientras ve y oye, huele, gusta y abraza a su esposo, puede ya cantar como la esposa en el Cantar de los cantares, compuesto para el ejercicio de la contemplación" (ANDEREGGEN 1997, p. 259); el texto latino se puede consultar en http:/ /www.thelatinlibrary.com/bonaventura. itinerarium.html: "Quibus sensibus recuperatis, dum sponsum suum videt et audit odoratur, gustat et amplexatur, decantare potest tanquam sponsa $\mathrm{Can}$ ticum canticorum, quod factum fuit ad exercitium contemplationis". También es importante notar lo que Andereggen dice: "Cada una de las tres virtudes teologales corresponde a algunos [sentidos] en particular. A la fe corresponde el oído y la vista. A la esperanza corresponde el olfato. A la caridad el gusto 
que le den consejo. La conclusión a que llegan es que debe vengarse violentamente, pero su esposa, Prudencia, le aconseja en cambio que no haga caso de semejante dictamen, sino que resuelva las cosas pacíficamente. Prudencia, quien se muestra como una mujer sabia, pues cita a muchas autoridades, se detiene en algún momento de su discurso sobre el nombre del esposo y dice:

Tu nombre, Melibeo, significa "hombre que liba miel". Has libado muchísima miel de dulces riquezas temporales y mundanas delicias y honores, que te han embriagado, y has olvidado a Jesucristo tu Creador. No le has prestado el honor y reverencia debidos, y no has observado las palabras de Ovidio, que afirma: "Bajo la miel de los bienes temporales se encubre el veneno que mata al alma". Y Salomón apostilla: "Si encuentras miel, sáciate; pero si la ingieres sin mesura, la vomitarás y te verás menesteroso y pobre (Chaucer 2006, p. 442).

Prudencia hace referencia a un manido tema con respecto a la apariencia engañosa del mundo ${ }^{5}$. Aquí se expone el doble

y el tacto" (p. 259). Si por medio de la prudencia vamos a aludir a las virtudes cardinales, aquí se recuerdan también las virtudes teologales.

${ }^{5}$ Lo anterior también está en consonancia con el tema mayor del Cuento de Melibeo, que tiene que ver con los consejos. En Disciplina clericalis, en el apartado que se les dedica, leemos: "Otro filósofo dijo también: desconfía del consejo dado por aquel a quien tú se lo pides, a menos que éste no sea a tu parecer de una fidelidad comprobada. Y otro filósofo: mientras que puedas, da a tu amigo consejos con miras al bien, aun si no quiere creerte. Es justo, en efecto, que le des buenos consejos, aun si como un insensato él no siga tu justo consejo" [consultado en la página a cargo de la Facultad de Teología de la Universidad Católica Argentina: http:// webs. advance.com.ar/]. Así como en ocasiones se advierte en el Libro de buen amor sobre el valor del libro ("açúcar dulce e blanco está en vil cañavera", 17d) y sobre las apariencias, las cuales no deben regir el juicio final de la obra, así también se aconseja mesura con las palabras dulces, que puede que encubran malas intenciones, o sobre el aparente provecho de las posesiones terrenas. Así pueden unirse estos temas y observarse el tópico de los amigos: por un lado, hay que probarlos para ver si son confiables a pesar de sus palabras laudatorias (así como ocurre al conde Lucanor en el primer exemplum), por otro, para ser un buen amigo hay que dar consejos provechosos. Prudencia actúa como buena amiga de su esposo, ya que le advierte de su mal juicio al no saber juzgar bien las palabras de sus falsos amigos y al señalar que se ha dejado llevar por placeres efímeros y mundanos. Sin duda, hacerlo por medio del análisis de su nombre y su relación con la miel es de interés para este texto, pero se inscribe en una tradición mucho más amplia, llena de lugares comunes. 
valor de la miel en cuanto que puede encubrir con su dulzura las malas intenciones de falsos amigos. Es la segunda cita, sin embargo, la que encuentra un mejor acomodo entre las que veíamos previamente. Saciarse con la miel es recomendable, pero caer en el exceso tiene efectos adversos.

Así como el nombre de la hija de Melibeo, Sofía, tiene una carga especial en lo que toca al conocimiento $-\mathrm{y}$ por lo tanto es sugerente que sea atacada en los órganos a cargo de los sentidos-, el de Prudencia también va a ser importante. Si pensamos en Melibeo como una persona que, así como libó de los placeres mundanos, también recurre a distintas personas para hacerse de una opinión, podemos relacionarlo con lo expuesto anteriormente respecto de las flores y el conocimiento. Melibeo, efectivamente, es una persona con conocimientos, pero sin una dirección moral clara. La función de Prudencia en el relato es marcar el camino ético de las acciones de Melibeo. Si se toma este planteamiento desde la perspectiva de la memoria en la Edad Media, es importante advertir las palabras de Frances Yates en The art of memory:

Towards the end of the De Inventione, Cicero defines virtue as "a habit of mind in harmony with reason and the order of nature" a stoic definition of virtue. He then states that virtue has four parts, namely Prudence, Justice, Fortitude, and Temperance. Each of these four main virtues he subdivides into parts of their own. The following is his definition of Prudence and its parts:

Prudence is the knowledge of what is good, what is bad and what is neither good nor bad. Its parts are memory, intelligence, foresight (memoria, intelligentia, providentia). Memory is the faculty by which the mind recalls what has happened. Intelligence is the faculty by which it ascertains what is. Foresight is the faculty by which it is seen that something is going to occur before it occurs (p. 20).

Más adelante dirá que "it is under memory as a part of Prudence that Albertus [Magnus] and Thomas [Aquinas] treat of it" (p. 57) ${ }^{6}$. De esta manera, el conocimiento que se almacena

${ }^{6}$ Carruthers (2008), en el subcapítulo "Memory and the habits of virtue”, señala lo mismo con respecto de la forma en que se leyó a Cicerón: "Albertus Magnus and Thomas Aquinas both make the conscious cultivation of memory and the practice of the memorial arts a moral obligation as well as a scholarly necessity" (p. 88). La prudencia tendrá un lugar primordial: "The hexis or orientation of the moral organism which disposes it to act righteously is prudence" (p. 87). 
y la inteligencia con la que se juzgan los acontecimientos del presente deben tener la prudencia como eje si se quiere llevar una vida recta.

Por lo anterior, Prudencia guía a Melibeo para tomar una decisión sensata. Al final del relato Melibeo da un traspié y concluye erróneamente: "les confiscaré todas sus riquezas y los desterraré de por vida", a lo que Prudencia responde: "esa sería una decisión cruel e indiscreta... si obraras así, te tildarían fácilmente de codicioso. De este vicio todos deben huir, ya que, como afirma el apóstol, «la raíz de todos los males es la codicia»" (Chaucer 2006, p. 459). Al final, Melibeo "dio gracias a Dios, fuente única de bondad y virtud, por haberle otorgado esposa tan discreta" (Chaucer 2006, p. 461), y dice a los agresores de su hija Sofía: "os perdono por entero todos los agravios, maldades e insultos que contra mí y los míos habéis cometido" (Chaucer 2006, p. 461). Melibeo opta por el perdón de manera virtuosa; sin embargo, para este texto es de mayor importancia señalar que rehuyó la codicia, ya que está relacionada con el exceso y el vicio.

La codicia como raíz de todos los males, ya señalada por Prudencia, es una idea contenida también en el Libro de buen amor: "De todos los pecados es raíz la Cobdiçia" (218a), evidente hipertexto de "radix enim omnium malorum est cupiditas" (1 Ti 6:10). La codicia se convierte en el vicio que desbancará a la soberbia como origen del resto de los males: "es el pecado natural y material, la pasión puramente terrenal" (Huizinga 2001, p. 38). Tanto la avaricia como la concupiscencia son expresiones de cupiditas, ambas presentes en los personajes de La Celestina ${ }^{7}$.

7 Vale la pena hablar de la relación entre cupiditas y la avaricia y entre cupiditas y la concupiscencia. Por un lado, como señala Huizinga, "por cupiditas, que como tal no tiene puesto en la serie de pecados capitales, se entiende en este texto avaritia [se refiere al de Timoteo], como se dice en otra lección del mismo... Es el pecado de aquel período en el que la circulación del dinero ha transformado y desligado de sus trabas tradicionales las condiciones en que se despliega el poder. La apreciación de la valía personal se torna una operación aritmética. Hay un espacio mucho mayor para la satisfacción de los apetitos más desenfrenados y para la acumulación de tesoros" (p. 38). En la mención de "los apetitos más desenfrenados" ya vemos que la codicia no se reduce al deseo y acaparamiento de bienes materiales. Por otro lado, PANOFsKY señala que "el concepto de caritas, originalmente limitado al «amor que Dios nos tiene» (San Juan I-IV, 16) fue después extendido al desinteresado amor a Dios y a sus semejantes. Pero, aun entonces caritas (appetitus boni, o amor Dei, o amor spiritualis) estaba en un agudo contraste con las diferentes 
Antes de evaluar cómo es que la falta de prudencia y la elaboración de la miel pueden iluminar nuestro entendimiento de los personajes, es necesario detenernos en al menos otra de las caras del discurso.

\section{El Discurso ES MIEL Y TEJIDO}

El símil entre la alcahueta y la abeja funciona gracias a su labor productora de miel que es discurso. Vimos cómo Celestina construye con palabras una Melibea para Calisto, y viceversa. El discurso de Celestina es un mediador entre los personajes, y así como lo he comparado con la miel, también está sujeto a otras analogías; quizá la más clara es la del discurso con el hilado. Además de la archisabida relación etimológica entre texto y tejido, en La Celestina las referencias al hilado recurrentemente tienen que ver con el discurso. Para los propósitos de este trabajo es necesario insistir en que hilado, palabras o miel refieren a lo mismo y en que, dependiendo del contexto, será más fructífero emplear uno u otro concepto. La miel, según advertí antes, funciona como medicamento, pero en el discurso del siguiente fragmento puede operar en un nivel superficial como 'medicamento' e 'hilado'. Al final del décimo auto, cuando Alisa pregunta a Celestina: “¿En qué andas acá, vezina, cada día?”, Celestina responde: "Señora, faltó ayer un poco de hilado al peso y vínelo a cumplir, porque di mi palabra". Melibea dirá a su madre que el propósito de la visita de Celestina era "venderme un poquito de solimán" (p. 440).

Detengámonos primero en Melibea. Russell comenta que "tanto Celestina como Melibea mienten de modo contradictorio a Alisa pues no han concertado entre sí una explicación" (p. 440). Eso es cierto en un nivel superficial, pero en el metafórico ninguna de las dos se contradice. Melibea responde a su madre que compró un poquito de solimán, cuyo uso medicinal era frecuente. Las palabras de Melibea a Lucrecia en el inicio del auto revelan que está enferma: “ $\mathrm{O}$, si ya veniesses con aquella medianera de mi salud!” (p. 426). Posteriormente, des-

formas de amor «sensual» comprendidas bajo el concepto cupiditas (appetitus mali, amor mundi, o amor carnalis)" (2010, p. 144). La codicia, o cupiditas, envuelve el amor por todo lo mundano y es por eso que puede ser la raíz de los pecados capitales; sin duda, el amor por los bienes materiales y el amor carnal son dos de sus avatares más recurrentes. 
cribirá sus síntomas: "Madre mía, que me comen este corazón serpientes dentro de mi cuerpo" (p. 428) ${ }^{8}$. El solimán de la enfermedad de Melibea es Calisto, en lo que se puede ver un rasgo de ironía trágica si se considera que el solimán fue contraindicado por sus efectos, que podían ser mortales, así como el destino de nuestra doncella ${ }^{9}$. Pero reparemos en que la lengua de Celestina también dará alivio a Melibea: "Parésceme que veo mi coraçón entre tus manos, fecho pedaços; el qual, si tú quisieses, con muy poco trabajo juntarías con la virtud de tu lengua" (p. 428). Hasta ahora, la palabra de Celestina, único modo de acceder a Calisto, es lo que ha aliviado la enfermedad de Melibea: discurso y remedio son uno mismo.

El tema del hilado es mucho más complejo de lo que en este texto se va a exponer; sin embargo, llama la atención que en el fragmento analizado Celestina diga a Alisa que "faltó

8 Robert Burton, en su Anatomy of melancholy, en el apartado "Symptoms or signs of love melancholy, in body, mind, good, bad, \&c.", cita: "Can a man, saith Solomon, Prov. vi. 27, carry fire in his bosom and not burn?" La acumulación de bilis negra puede ocasionar males como los descritos por Melibea en el pecho: "la ysquierda teta es su aposamiento" (p. 430). JEAN STARobinski (2016, p. 39), siguiendo a Galeno, distingue entre tres tipos de melancolía según la parte del cuerpo en que se localizan. La tercera es "una afección melancólica situada primitivamente en el nivel del estómago y de los órganos digestivos -el hipocondrio-, que afecta el encéfalo por exhalaciones y vapores". Los hipocondrios se localizan en la parte inferior del pecho. Este tipo de melancolía puede ocasionar "infarto, estasis, obstrucción, inflamación en la región de los hipocondrios" (p. 38). Si consideramos que "Galeno atribuirá a la atrabilis una vitalidad extraña: la atrabilis «muerde y ataca la tierra, se infla, fermenta, provoca ampollas semejantes a las burbujas que salen de la sopa en ebullición»" (pp. 22-23), y que también "un tratamiento hipocrático" recoge entre otros síntomas que "el enfermo parece tener en las vísceras una espina que le pica" (p. 24), no resulta imposible pensar que Melibea esté enferma de amor y por eso busca un remedio. Por eso se referirá a Celestina como un médico capaz de librarla de su dolor: "Amiga Celestina, mujer bien sabia y maestra grande, mucho has abierto el camino por donde mi mal te pueda especificar. Por cierto, tú lo pides como mujer bien esperta en curar tales enfermedades" (p. 430).

9 Por medio del CORDE he encontrado en el Libro de acuerdos del Concejo madrileño (ca. 1492): "En lo del solimán no votó el señor Pedro Çapata. Vedamiento que no vendan rejalgar ni solimán. Mandaron los dichos señores pregonar e hizieron por ley e ordenança para agora e daquí adelante, que persona alguna así boticario como espeçiero e otra qualquier no sea osado de vender rejalgar nin solimán nin otra ponçoña alguna, so pena de muerte por quanto no aprovecha cosa alguna y por espiriençia pareçe los daños que dello se siguen, que han muerto quatro o çinco personas que lo an tomado el dicho solimán”. 
ayer un poco de hilado", ahora que ha concluido la conquista de su hija. Es el hilado lo que le da motivo para entrar a casa de Melibea, como la alcahueta ya había explicado a Calisto: "Vender un poco de hilado con que tengo caçadas más de treinta de su estado" (p. 341). Esta artimaña está dentro de lo que Celestina nombra como "el proceso de mi habla y la causa que tuve para entrar" (p. 340). Los procesos del habla y del hilado están íntimamente unidos; en un plano simbólico veremos que son lo mismo. Celestina, después de la primera visita a casa de Melibea, obtiene un cordón: "En pago de tu buen sufrimiento, quiero cumplir tu demanda y darte luego mi cordón” (p. 323). Cuando la prenda sea entregada brevemente a Calisto, desatará una de las reacciones más memorables de la obra: “ $\mathrm{O}$ nuevo huésped! ¡O bienaventurado cordón, que tanto poder y merescimiento toviste de ceñir aquel cuerpo que yo no soy digno de servir! ¡O ñudos de mi pasión, vosotros enlazastes mis desseos!" (p. 349). Leamos con atención las palabras "ñudos de mi pasión". Celestina sale de casa de Calisto con el cordón ("déxame llevar el cordón, porque dél tengo necessidad”, p. 356), que se constituye en nuevo pretexto para que la medianera entre a casa de Melibea. Lucrecia dice: "Mi venida, señora, es lo que tú sabrás: pedirte el ceñidero... Madre, que vamos presto y me des el cordón" (pp. 422-423), aunque, de hecho, ya se había pactado que Celestina regresaría por la oración a "Sancta Polonia" (p. 318). Por todo este itinerario, en el que Celestina teje una red que involucra a los amantes por medio de palabras, hilado y cordón, es de suma importancia que termine el auto décimo diciendo que vino a "cumplir" el poquito de hilado que había faltado. La red de Celestina está completa ${ }^{10}$.

Esto no es gratuito de ninguna manera. Así como se puede equiparar el discurso con la miel, también es posible asomarse a la tradición amorosa para ver cómo su discurso participa

10 Alan Deyermond (1977) trata el tema de manera distinta y muy erudita. La diferencia esencial entre este texto y la postura de Deyermond es que aquí no se argumenta que es el Diablo el responsable de los cambios en los personajes. A pesar de eso, ambos textos coinciden en dos aspectos fundamentales. Por una parte, la equivalencia entre hilado, cordón, cadena: "girdle is exchanged for gold chain, just as skein had been exchanged for girdle" (p. 9); por otra, se hace mención de la red, pues el hilado es "strong enough to make a net to trap Melibea" (p. 7). Deyermond también alude a las palabras que Celestina dice a Sempronio acerca de Pármeno: "será de los nuestros; darnos ha lugar a tender las redes sin embarazo por aquellas doblas de Calisto" (p. 6). 
de un léxico significativo por cuanto evoca las redes y los tejidos. Recordemos que en otros ejemplos literarios la unión de un par de amantes también está simbolizada por elementos que semejan hilos o cordones. Es particularmente famoso el ejemplo de Tristán, el Rey Marco e Iseo. Como sabemos, el cabello rubio de Iseo, que lleva una golondrina, va a ser catalizador para que Tristán, aunque por encargo de su tío, vaya en su búsqueda. También en Cligès de Chrétien de Troyes, Alejandro recibe una camisa de parte de la reina. Entre hilos de oro se encuentra un cabello de Soredamor que brilla más que ninguno. Cuando el caballero escucha a su dama narrar que ella tejió la camisa, Alejandro sufre una pasión equiparable, hasta cierto punto, con la de Calisto por el cordón: "no se atreve a llevar la camisa hasta los ojos y hasta la boca, donde la habría llevado con sumo gusto, si supiera que no le veían... cuando tiene ocasión, besa la camisa más de cien mil veces" (pp. 93-94). Ioan P. Culianu, en su libro Eros y magia en el Renacimiento, apunta:

En efecto, ¿qué hace el enamorado, con todos sus gestos, palabras, favores y obsequios, si no crear una red mágica alrededor del objeto de su amor? Todos los medios de persuasión que pone en funcionamiento son otros tantos medios mágicos cuya finalidad es atar al otro. Ficino mismo utiliza, en una ocasión, el término rete, que significa "malla" o "red". Hablando con propiedad, se puede decir que el amante y el mago hacen lo mismo: lanzan sus "redes" para apoderarse de ciertos objetos, para atraerlos y arrastrarlos hacia ellos (p. 130).

Culianu se acerca al De vinculis in genere, de Giordano Bruno, para entender cómo una persona, a la que se referirá como "mago", puede manipular la voluntad de los individuos. Hay paralelismos con Celestina que dan luz acerca del subtexto que anima al personaje. Por ejemplo, señala Culianu que "cuantos más conocimientos tenga un manipulador sobre aquellos que quiere «vincular», mayor serán sus probabilidades de éxito puesto que sabrá escoger el momento propicio para crear el vinculum" (p. 133). El mago hará uso del vínculo para manipular a los individuos involucrados y obtener de ellos lo que desea. Otro aspecto que acerca a Celestina a las operaciones brunianas surge cuando la alcahueta dice a Melibea:

sabe que no ay cosa más contraria en las grandes curas, delante los animosos çurujanos, que los flacos coraçones, los quales con su 
gran lástima, con sus dolorosas hablas, con sus sentibles meneos, ponen temor al enfermo, hazen que desconfíe de la salud, y al médico enojan y turban... es muy necessario para tu salud que no esté persona delante y así que la deves mandar salir. Y tú, hija Lucrecia, perdona (p. 433).

Culianu, a su vez, señala que "para que salga con éxito una operación -Bruno no se cansa nunca de decirlo-, tanto el operador como los sujetos deben estar plenamente convencidos de su eficacia. La $f e$ es la condición previa de la magia: «No existe operador -sea mago, médico o profeta-que pueda desempeñar nada si no existe una fe previa en el sujeto»" (p. 136). A fin de cuentas, vemos que la persona de la que habla Bruno es equiparable a un médico como también lo es nuestra alcahueta. Para su propósito final, "manipular a los individuos según sus disposiciones afectivas", se valdrá del eros, pues "entre los vínculos, el más fuerte es el de Venus" (p. 141). Lo que ha hecho Celestina con el hilo-cordón-discurso es tejer una red que vincula a los amantes y, de paso, a los criados. Sin embargo, Culianu también apunta que, según Bruno, "el manipulador no tiene derecho a utilizar su poder sobre las masas con fines egoístas" (p. 138). Estas palabras sirven como advertencia para el lector del texto celestinesco; difícilmente la alcahueta va a tener un buen final, ya que sabemos que su más caro propósito es "medrar" con este negocio.

Codicia de la Abeja. LA MUerte ocasionada POR LA Miel

La recompensa final de todo el proceso de manipulación es la cadena que Calisto da en pago a la alcahueta: "En lugar de manto y saya, por que no se dé parte a oficiales, toma esta cadenilla" (pp. 446-447). El discurso de la medianera se ha transformado a raíz de este premio, así como el último eslabón de la red, la cadenilla, que antes fue cordón y, antes, hilado. Celestina, que ha actuado de manera egoísta y codiciosa, intentará quedársela, aun cuando debía dividirse entre ella, Pármeno y Sempronio, quien dice: "antes que venga el día quiero yo yr a Celestina a cobrar mi parte de la cadena” (p. 475), pero ella no encuentra razón para compartirla: "Qué tiene que hazer tu galardón con mi salario, tu soldada con mis mercedes" (pp. 478-479). Después dirá que el valor de la cadena "no era mucho" (p. 479) y, por si 
fuera poco, habla sobre la posibilidad de que unos familiares y conocidos suyos la hayan robado. Luego, termina declarando a Sempronio: "Si algo vuestro amo a mí me dio, devés mirar que es mío” (p. 480). Esta débil argumentación llevará a Sempronio y a Pármeno a hacerle frente, y a ella, la alcahueta, a su muerte.

A partir de la revisión de la miel y de la abeja, del cuento de Chaucer y de la lectura que Culianu hace de Bruno, se puede ver que la muerte de Celestina no implica ninguna sorpresa. He mencionado que la miel, si bien ha corrido en general con buena fama entre los clásicos y quienes los retoman, también puede tener connotaciones negativas. Plinio señala que "algunas veces las abejas mismas se buscan la causa de su muerte, cuando se dan cuenta de que les quitan la miel, y la devoran con ansia... les hace daño también su propia miel y si se les unta por detrás mueren" (IX, 67). Las abejas, entonces, pueden provocarse la muerte si, ante el peligro inminente de un despojo, comen excesivamente de la miel. Sin duda, esto recuerda a la alcahueta, quien se niega a compartir la cadenilla -caracterizada ya como uno de los avatares de su discurso, al igual que la miel-por atesorarla más allá de lo razonable. Es la codicia la condena de Celestina.

De la misma manera, si nos adentramos en la analogía, ya explicada, del arte de la memoria y recordamos que ésta es parte de la prudencia, deducimos que la falta de Celestina es actuar sin ella. Prudencia aconseja a Melibeo en contra de la codicia, porque es la raíz de todos los males. Celestina, si bien domina el discurso, no lo ejerce virtuosamente, lo que se castigará en la diégesis de la obra.

Por último, si se observa el caso celestinesco desde la lectura de Culianu, es cierto que la alcahueta teje una red que vincula a los personajes y logra, durante buena parte de la diégesis, manipularlos exitosamente. Celestina, sin embargo, no es capaz de permanecer ajena a las relaciones que forja entre todos los vinculados. Culianu señala a este respecto:

Bruno exige del operador una labor sobrehumana: primero debe guardar inmediatamente y sin equivocarse las diferentes informaciones según su origen y, después, debe hacerse completamente inmune frente a cualquier emoción provocada por causas externas. En definitiva, se supone que ya no reacciona ante ningún estímulo externo. No debe dejarse conmover ni por la compasión, ni por el amor del bien y de lo verdadero, ni por nada, para evitar ser "vinculado" a su vez (pp. 135-136). 
Celestina no va a dejarse conmover por el amor del bien; en cambio, dará entrada a la avaricia y se dejará afectar por los vínculos que establece, por ejemplo, con Pármeno y Areúsa ${ }^{11}$, red que utilizará para beneficiarse. Sin embargo, tanto su mal propósito como su mal manejo de la red la llevarán al trágico final que conocemos.

El texto celestinesco, además de estar lleno de resonancias y de jugar constantemente con las tradiciones que le anteceden, se adelanta a las ideas que vendrán después, como hemos visto con el texto de Bruno. La Celestina es una obra que ha logrado generar experiencias estéticas a lo largo del tiempo gracias a la manera en que explota diversos recursos literarios. Queda ahora, con base en la revisión que se ha hecho en las páginas precedentes, señalar algunos aspectos de los nombres de dos personajes: Celestina y Melibea.

Celestina, la QUe Recorre el Gielo. Melibea, LA DE LA VOZ DULCE

No ha escapado a la crítica la ironía imbricada en el nombre de la alcahueta. Si existe un personaje poco celestial en la obra es Celestina. Pero el gesto irónico puede cargarse de más fuerza si reconocemos que hay elementos que hacen coherente que se le haya dado ese nombre; apuntamos una posibilidad aquí: Celestina es celeste porque es una abeja, una abeja que recorre los cielos y va a diversas flores para lograr la conquista de Melibea. También será la abeja en que no se puede confiar; bien dice Pármeno, cuando Calisto lo manda a llamar al sastre para hacer un manto y una saya: "A la vieja todo, por que venga cargada de mentiras, como abeja, y a mí que me arrastren" (p. 347). Celes-

11 Pensemos en el momento en que Celestina expresa su deseo de ver a Areúsa: "Déxame mirarte toda a mi voluntad, que me huelgo", a lo que ésta responde: "¡Passo, madre! No llegues a mí, que me fazes coxquillas y provócasme a reýr, y la risa acreciéntame el dolor" (p. 372). No es posible más que interpretar que Celestina no sólo vio a Areúsa, sino que la tocó al menos un poco. Más adelante, ya vinculados Pármeno y Areúsa por el arte celestinesco, la medianera recrimina a la joven que pida a Pármeno esperar a que ella se vaya para dar rienda suelta a su deseo: “QQué son estas extrañezas y esquividad, estas novedades y retraymiento?... nunca el viejo ni la vieja echava de mi lado, ni su consejo en público ni en mis secretos" (p. 380). Celestina se deja llevar por la cupiditas, por lo cual no le es posible permanecer ajena a la red que ella misma ha tejido. 
tina es una abeja que va y viene con un discurso engañoso; en la forma en que se construye su personaje resuena la tradición a la que alude Pármeno, que la caracteriza como "hieroglífico del adulador" (Covarrubias, f. 3v): sus elogios son la miel que encubre sus verdaderas intenciones. Celestina es una abeja que, como tal, recoge el sudor del cielo para convertirlo en miel, que lleva en la boca palabras dulces para cada uno de los personajes que manipula. Celestina es el orador que como la abeja recoge de diversas fuentes el conocimiento que necesita para fabricar su discurso. Celestina está en el cielo porque es una abeja. Si bien este pequeño rasgo puede colocar a la alcahueta en las esferas del firmamento, serán todas las connotaciones de lo celestial las que se verán frustradas en la obra para dar lugar a la ironía. Celestina es celeste, pero no celestial.

A partir de la muerte de Celestina, Melibea será quien ejerza el discurso. Mariel A. Palma (2006) bien señala que Melibea

se levanta como la portadora de la palabra primigenia, la que inventó Celestina, la que trajo de la esfera discursiva del mundo exterior al que la doncella estaba negada por definición. Y abre la puerta, y deja salir sus deseos y los impone sobre sus actos, ya nadie dirige su acción más que ella misma, porque ella es la única poseedora del discurso extraoficial, por eso cuando muere con ella muere el mundo de La Celestina, porque ya no transfiere la palabra (p. 99).

Si hacemos caso de lo que dice Palma, Melibea va a honrar su nombre. Es ella quien recibe el arte del discurso de Celestina. Así como Melibeo ha libado de distintas flores, Melibea va a mostrar mucha elocuencia en sus discursos. No sólo ha leído varios "antiguos libros", sino que argumenta perfectamente por qué no quiere tomar marido: "no quiero ensuciar los ñudos del matrimonio" (p. 536), y a partir de esto cita como ejemplo a Venus, Mirra, Semíramis, Thamar y remata con Pasifae (pp. 537-538), para ilustrar los pasos que no quiere seguir. Melibea va a configurar su discurso según sus deseos y va a actuar de acuerdo con ellos. Lamentablemente, esto la llevará también a la muerte. No es gratuito que unas de sus últimas palabras sean:

Algunas consolatorias palabras te diría antes de mi agradable fin, coligidas y sacadas de aquellos antigos libros que tú, por más aclarar mi ingenio, me mandavas leer; sino que ya dañada la memoria, con la grand turbación, me las ha perdido (pp. 589-590). 
Melibea, una mujer que, como los exégetas, estudió libros antiguos y fue capaz de arreglar esos conocimientos para fraguar un discurso elocuente a manera de los oradores, ahora reconoce que su memoria, turbada por la tristeza y el mal de amor, es incapaz siquiera de invocar sentencias. Melibea es caracterizada como una mujer que domina el discurso, que tiene una memoria educada y una educación letrada, pero también como alguien que se ha dejado llevar por sus pasiones. No ha sido la prudencia ni la virtud el norte de la dama, por cuanto no es de extrañar que comparta el mismo destino con su antecesora Celestina.

En este artículo se ha revisado la caracterización de Celestina como abeja, de los personajes como flores y del discurso como miel. Se ha expuesto además que los personajes y las palabras no son estáticos, toda vez que se transforman constantemente -Calisto en flor y remedio, el discurso en miel y tejido-, de lo cual no sólo se pueden establecer analogías, sino seguir la coherencia que guardan unas con otras hasta el final de la obra. Asimismo, se ha explorado la dualidad valorativa de la miel y de las abejas gracias al trasfondo intelectual que se sustenta ya sea en las ars memoriae o en los textos científicos. También, el acercamiento a los personajes desde varias perspectivas -el Cuento de Melibeo, el De vinculis in genere de Bruno- ha servido para desentrañar la complejidad que los reviste, desde la dimensión ética hasta las connotaciones de sus nombres. La Celestina, en fin, es una obra labrada de muchos tejidos, y este texto es apenas un hilo del que podemos tirar.

\section{REFERENCIAS}

Andereggen, Ignacio 1997. "El ascenso contemplativo filosófico y místico según el Itinerarivm mentis in Devm", Sapientia, 52, 202, pp. 247-277.

Aristóteles 1992. Investigación sobre los animales. Trad. Julio Pallí Bonet, Gredos, Madrid.

Buenaventura, SAn. Itinerarium mentis in Deum, http:/ / www. thelatinlibrary. com/bonaventura.itinerarium.html.

Burton, Robert. Anatomy of melancholy, http:// www.gutenberg.org/ files/ 10800/10800-h/ampart3.html.

Carruthers, Mary 2008. The book of memory. Cambridge University Press, Cambridge.

Caxton's Chaucer. En http:// www.bl.uk/ treasures/ caxton/homepage.html. Sagrada Biblia 1968. Versión de Eloíno Nácar y Alberto Colunga, BAC, Madrid. 
Chaucer, Geoffrey 2006. Cuentos de Canterbury. Trad. Pedro Guardia Massó, Cátedra, Madrid.

Clemens, Raymond 2007. Introduction to manuscript studies, Cornell University Press, Ithaca.

CORDE: Real Academia Española: Banco de datos [en línea]. Corpus diacrónico del español, http:/ / www.rae.es.

Covarrubias, Sebastián de 1611. Tesoro de la lengua castellana, Luis Sánchez, Madrid.

Culianu, IoAn P. 2007. Eros y magia en el Renacimiento. Trads. Neus Clavera et al., Siruela, Madrid.

Deyermond, Alan 1977. "Hilo-cordón-cadena: Symbolic equivalence in $L a$ Celestina", Celestinesca, 1, 1, pp. 6-12.

Huizinga, Johan 2001. El otoño de la Edad Media. Versión de José Gaos, Alianza, Madrid.

Juan Manuel 2003. El conde Lucanor. Ed. José Manuel Blecua, Castalia, Madrid.

Lacan, Jacques 2013. Libro 7. La ética del psicoanálisis. Trad. Diana S. Rabinovich, Paidós, Buenos Aires.

Palma, Mariel A. 2006. "Guía tú mi lengua". La importancia de la palabra en "La Celestina”, tesis, Universidad Nacional Autónoma de México, México.

PANOFSky, Erwin 2010. Estudios sobre iconología, Alianza, Madrid.

Pedro Alfonso. Disciplina clericalis. Trads. Francisco Gil et al., http:// webs.advance.com.ar/ pfernando/ DocsIglMed/pedro_alfonso_ DC.html\#\%5B1.

Plinio 2002. Historia natural. Trads. Josefa Cantó et al., Cátedra, Madrid.

Rojas, Fernando de 2001. La Celestina. Comedia o tragicomedia de Calisto y Melibea. Ed. Peter E. Russell, Castalia, Madrid.

Ruiz, Juan 1990. Libro de buen amor. Ed. Jacques Joset, Taurus, Madrid.

SÉnecA 1989. Epistolas morales a Lucilo. Trad. Ismael Roca Meliá, Gredos, Madrid.

Starobinski, Jean 2016. La tinta de la melancolía. Trad. Alejandro Merlín, Fondo de Cultura Económica, México.

Telfer, W. 1927. "Bees in Clement of Alexandria", The Journal of Theological Studies, 28, 110, pp. 167-178.

Troyes, Chrétien de 1993. Cligès. Trad. Joaquín Rubio Tovar, Alianza, Madrid.

Virgilio Marón, P. 2008. Bucólicas. Geórgicas. Apéndice Virgiliano. Trads. Tomás de la Ascensión et al., Gredos, Madrid.

Yates, Frances 1999. Selected works. T. 3: The art of memory, Routledge, New York. 